\title{
ENRAIZANDO A LEI 10639/03: LITERATURAS AFRICANAS NA EDUCAÇÃO BÁSICA
}

\author{
ROOTING LAW NUMBER 10639/03: AFRICAN LITERATURES IN BASIC \\ EDUCATION
}

ENRAIZANDO LA LEY 10639/03: LITERATURAS AFRICANAS EN LA EDUCACIÓN BÁSICA

Sílvia Barros ${ }^{1}$

\section{RESUMO}

Este artigo tem como objetivo discutir os avanços feitos e as lacunas persistentes na implementação da lei 10 639/03 no ensino básico. Apresentamos, também, perspectivas de aplicação da lei na educação básica em aulas de português do ensino fundamental em escolas públicas. Parte-se da perspectiva de que a presença de textos de autoria africana e afrodiaspórica atua tanto na difusão da história, cultura e literatura, como permite o conhecimento das raízes culturais de muitos dos indivíduos que estão nas fileiras escolares e não reconhecem a África como matriz de arte e ciência, contribuindo, também, para uma educação antirracista.

PALAVRAS-CHAVE: literaturas africanas, educação básica, educação antirracista, 10 $639 / 03$

\section{ABSTRACT}

This article aims to discuss the progress made and the persistent gaps in the implementation of law number 10639/03 in basic education. We also present perspectives of law enforcement in basic education in Portuguese classes of elementary education in public schools. It is based on the perspective that the presence of African and Afro-Diasporic authorship texts

1 Professora do Departamento de Português e Literaturas de Língua Portuguesa do Colégio Pedro II. Integrante do NeabCP2 e vice-coordenadora da especialização em Educação para as relações étnico-raciais no ensino básico. E-mail: silvialetras2003@yahoo.com.br 
acts as much in the diffusion of history, culture and literature as it allows the knowledge of the cultural roots of many of the individuals that are in the school ranks and do not recognize Africa as a matrix of art and science, also contributing to anti-racist education.

KEYWORDS: African literature, education, anti-racist education

\section{RESUMEN:}

Este artículo tiene como objetivo discutir los avances hechos y las lagunas persistentes en la implementación de la ley 10639/03 en la enseñanza básica. Presentamos, también, las perspectivas de aplicación de la ley en educación básica en las clases de portugués de la educación primaria en las escuelas públicas. Se parte de la perspectiva de que la presencia de textos de autoría africana y afrodiaspórica actúan en la difusión de la historia, cultura y literatura y permiten el conocimiento de las raíces culturales de muchos de los individuos que están en las escuelas y no reconocen África como matriz del arte y la ciencia, contribuyendo, también, a una educación antirracista.

PALABRAS-CLAVE: literatura africana, educación, educación antirracista

\section{Introdução}

Após uma longa história de lutas e reivindicações que levantaram as necessidades de ações afirmativas para os negros, o movimento negro brasileiro conquistou a promulgação da lei 10.639, em 2003. O entendimento de que a criação de uma nova sociedade, com o fim da ditadura, deveria incluir a luta contra o racismo e os conhecimentos sobre África como valores universais, colocou a escola no centro das estratégias de ações para essa nova sociedade, o que foi materializado pela modificação na lei de diretrizes e bases (9394/96).

A lei completa 10.639/2003, que completou quinze anos em 2018, versa sobre a obrigatoriedade de ensinar a história, a cultura, as literaturas africanas e a afro-brasileira, em todos os níveis de ensino, no território brasileiro. $\mathrm{O}$ artigo 26 afirma que:

Nos estabelecimentos de ensino fundamental e médio, oficiais e particulares, torna-se obrigatório o ensino sobre História e Cultura Afro-brasileira.

$\S 1^{\circ}$ O conteúdo programático a que se refere o caput deste artigo incluirá o estudo da História da África e dos africanos, a luta dos negros no Brasil, a cultura negra brasileira e o negro na formação da sociedade nacional, resgatando a contribuição do povo negro nas áreas social, econômica e política pertinentes à História do Brasil.

$\S 20$ Os conteúdos referentes à História e Cultura Afro-brasileira serão ministrados no âmbito de todo o currículo escolar, em especial nas áreas de Educação Artística, de Literatura e História Brasileiras. (BRASIL, 2003, art. 26-A) 
A lei não informa apenas que devemos falar sobre a cultura africana e afro-brasileira, mas inclui conteúdo sobre a luta dos negros e a presença desse sujeito na formação da sociedade nacional. Ou seja, o texto traz uma mensagem metalinguística: a lei criada a partir da luta dos movimentos negros garante que se discuta nas aulas das mais diversas disciplinas questões da luta do povo negro no Brasil. Tal ação só pode ser empreendida também com muita luta dentro dos estabelecimentos de educação pública ou privada, pois ainda há uma série de entraves para sua aplicação e, mais ainda, para a naturalização dos conteúdos por ela propostos no cotidiano das salas de aula nas mais diversas disciplinas.

Existe um discurso bastante corrente, e não podemos afirmar que seja mentiroso, sobre a deficiência nas licenciaturas no que diz respeito a disciplinas que versem sobre a África e sobre a cultura afro-brasileira, além da falta de oferta de formação continuada para os docentes em atuação. Tal discurso escancara o racismo institucional brasileiro, mas também informa sobre a necessidade de autonomia pedagógica e busca por uma autoformação.

No que diz respeito ao ensino de língua e literatura, temos a oportunidade de compartilhar a língua oficial com cinco países africanos, além de guardar a herança linguística de diversos grupos trazidos ao Brasil como força escrava durante a colonização. Com isso, o trabalho com as literaturas africanas, não deve ser compreendido como um projeto a ser desenvolvido apenas no mês de novembro, mas como material cotidiano das aulas. Essa é uma proposta que oferecemos para a efetivação de uma lei que não foi imposta, pois foi fruto do processo democrático de reivindicação por direitos de igualdade para os negros.

Cabe, desse modo, salientar o papel privilegiado do discurso literário nesse caminho de luta por visibilidade para os que foram subalternizados socialmente:

A literatura pode oferecer um acesso a diferentes perspectivas sociais mais rico e expressivo do que, por exemplo, aquele proporcionado pelo discurso político em sentido estrito. Por isso mesmo, é um território em disputa, onde está em jogo a possibilidade de dizer sobre si e sobre o mundo, de se fazer visível dentro dele. Ignorar essas reivindicações em torno do literário costuma ser uma maneira de reafirmá-lo como um atributo sobrenatural e trans-histórico, fruto de um "talento" que se fixa em alguns indivíduos especiais, em vez de ser uma prática social, que tem a ver com a produção de hierarquias que beneficiam alguns e excluem outros. (DALCASTAGNÈ, 2014, p. 68)

Dar conhecimento sobre as diferentes realidades africanas por meio da literatura é assumir a diversidade do continente e reafirmar que a arte e a literatura não têm como matriz única a Europa.

\section{África na escola: primeiros passos}

Em uma sala de aula repleta de estudantes negros ecoam muitos elementos vindos da 
África: a música, a religião, a dança, os falares. No entanto, esses meninos e meninas, ao serem indagados sobre seus conhecimentos acerca dos países que compõem o continente africano, dizem pouco ou nada saber. Quando sabem, falam de pobreza, fome e escravidão. A aplicação da lei 10.639, nas mais diversas disciplinas, deveria evocar conhecimentos que desconstruíssem tais estereótipos e promovessem o encontro desses estudantes com as matrizes culturais que nos constituem como povo. Em última instância, esses conhecimentos deveriam criar uma ideia de pertencimento e orgulho em relação a uma história que extrapola os quinhentos e poucos anos do Brasil colonizado.

Para fazer um trabalho efetivo em língua portuguesa e suas literaturas que contemple a lei 10.639, é necessário ultrapassar as práticas superficiais e pontuais, frequentemente desenvolvidas nas escolas como forma de "ficar quites" com o cumprimento da lei. Entre essas práticas estão, por exemplo, palestras, debates ou conversas sobre o racismo que, com frequência, evocam o mito da democracia racial por meio do discurso da igualdade e da miscigenação brasileira. Obviamente, a lei 10.639/03 é um mecanismo para uma educação antirracista; esse recurso, porém, tem como objetivo explorar elementos culturais e históricos que nos aproximam e que nos diferenciam e não que anulem a questão por meio de frases de efeito vazias.

Algumas práticas que se propõem ir mais adiante na discussão, como a leitura de textos que trazem elementos das culturas africanas, muitas vezes recaem somente no exotismo, na apresentação dos usos e costumes do "outro" que em nada refletem quem nós somos. As Diretrizes Curriculares Nacionais para a Educação das Relações Étnico-Raciais e para o Ensino de História e Cultura Afro-Brasileira e Africana, com o objetivo de reforçar a ideia de que, ao estudar sobre a África e os africanos, estudamos sobre nós mesmos, explicam que:

Precisa o Brasil, país multi-étnico e pluricultural, de organizações escolares em que todos se vejam incluídos, em que lhes seja garantido o direito de aprender e de ampliar conhecimentos, sem ser obrigados a negar a si mesmos, ao grupo étnico/racial a que pertencem e a adotar costumes, ideias e comportamentos que lhes são adversos. E estes, certamente, serão indicadores da qualidade da educação que estará sendo oferecida pelos estabelecimentos de ensino de diferentes níveis (BRASIL, 2013, p. 18).

Sabemos que, no processo de escravização dos africanos, nossos antepassados foram obrigados a adotar comportamentos que lhes eram adversos, mas que, mesmo assim, muitas de suas formas de ver o mundo e de viver nele perduraram pelas mais diversas linguagens que expressam a fé, a voz e as tradições. Tais formas de existir são frequentemente reprimidas ainda hoje e são ignoradas pelas instituições de prestígio. $O$ trecho citado enfatiza que a lei também foi criada para dar lugar na escola às heranças culturais que grande parte dos estudantes carrega. Com isso, simultaneamente, se dá a valorização devida a essas raízes que são partilhadas por grande parte dos brasileiros, inclusive aqueles em que a parcela africana do sangue não se 
apresenta na aparência.

\section{O papel das Literaturas Africanas}

Nesse processo, as aulas de Língua Portuguesa e Literatura podem assumir um papel muito importante, até mesmo protagonista pela proeminência que a língua tem na nossa forma de pensar e agir, de trazer ao centro da sala de aulas produções africanas. Antes de mais nada, é necessário pensar que existe um imaginário sobre a África que enxerga o continente como um país, um monólito exótico e faminto. Tais ideias reverberam na escola, pois imagens e relatos sobre o território africano anterior à colonização europeia foram historicamente substituídos por uma imagem de atraso. Como afirma Munanga:

Não faltam imagens atuais sobre a África, raramente são mostrados os vestígios de um palácio real, de um império, as imagens dos reis e ainda menos de uma cidade moderna africana construída pelo próprio ex-colonizador. As imagens geralmente exibidas mostram uma África dividida e reduzida, enfocando doenças endêmicas, aids, guerras, miséria e pobreza $(2009$, p. 11).

Há um vazio de imagens e narrativas positivas sobre a África e, mais ainda, há um vazio de conhecimento sobre os países que compõem o continente. A lei 10.639/03 tem como objetivo guiar os educadores para um planejamento que desfaça os equívocos e estereótipos que geram preconceitos contra a África e racismo contra seus descendentes brasileiros. Sabemos que grande parte dessa função deve ser exercida pelos docentes de História e Geografia, no entanto, há um papel importante dos profissionais de letras que lecionam tanto Língua Portuguesa quanto Literatura que consiste em apresentar, pela narrativa, poesia e outros gêneros, uma África múltipla, criadora de conhecimentos e beleza, que carrega em seus textos parte de sua história e de seu devir.

Com isso em mente, comentarei brevemente sobre o trabalho com três contos africanos: “A Indústria de tambores”, de Dina Salústio, "O recreio das dez e meia”, de Carlos Lopes e "O Kazukuta", de Ondjaki. Propositadamente, o pequeno corpus que se apresenta aqui não discute questões como a negritude, por exemplo, nem traz descrições de personagens negros, vilas tradicionais ou elementos da religiosidade; essa foi uma estratégia de quebra de expectativa para as aulas em que os textos foram lidos. No entanto, entendemos que, além de tais questões negritude, religiosidade etc. - serem de extrema importância, elas subjazem todas as narrativas selecionadas.

\section{"A Indústria de tambores"}

O conto da cabo-verdiana Dina Salústio mostra a relação entre modernidade e desenvolvimento, ou seja, os aparatos tecnológicos que chegaram a partir da colonização, no caso os 
jornais e o rádio, e os aparatos tecnológicos tradicionais: os tambores. Todos eles com função de comunicar, trocar mensagens boas ou más. O conto apresenta a proposta feita por um funcionário público a seus superiores que permitiria que ele viajasse para o exterior para fazer um curso de três anos de fabricação de tambores, proporcionando, após seu retorno à ilha, a retomada da tradição comunicativa dos tambores. O toque dos tambores seria um instrumento do aparelho judiciário, permitindo ao cidadão sua autodefesa diante de alguma ofensa moral proferida contra si.

O trabalho com esse conto, especialmente em anos como a primeira série do ensino médio, quando as discussões sobre o que é literatura, o que é linguagem e comunicação estão se tornando mais estruturadas, permite entender que, primeiramente, os sistemas de comunicação e justiça levados pelo elemento europeu não são os únicos existentes e possíveis. O tambor é o eco da luta pela tradição, pela justiça e pela identidade do povo. Salústio escreve esse texto no contexto pós-colonial, quando

o colonizado quer se afirmar como autóctone resultado de si por si mesmo, nativo e ponto final, sem assimilações, sem imposições e, sim, com vivências e costumes do lugar. De posse dessa consciência, se organiza, luta, faz revolução e se torna independente. Neste processo, no caso das culturas africanas, o tambor passa a ecoar como resistência à opressão, à escravidão e ao trabalho forçado, constituindo-se em símbolo de resistência e porque não dizer de unificação dos africanos em diáspora (MIRANDA; SANTOS, 2013, p. 129).

O artigo "Linguagens em diálogo no ensino da cultura e da história africanas", de Maria Geralda de Miranda e Rosenilda Roberto dos Santos, trata da presença do tambor como elemento fundamental da cultura africana, presente em narrativas de diferentes países e enfoca o fato de que essa linguagem não verbal deve fazer parte do ensino de cultura e história africanas.

A compreensão de que os tambores unificam os africanos em diáspora torna-se também um componente importante de interpretação desse texto, pois manifesta a familiaridade dos brasileiros (afrodescendentes ou não) com a cultura musical africana. O conto de Salústio aponta para uma ilha cabo-verdiana em que já chegaram elementos considerados modernos, inclusive os caminhos burocráticos que levam o homem a fazer seu requerimento de bolsa de estudos são semelhantes aos que conhecemos. O ponto de virada proposto pela autora é a retomada da tradição, celebrada pela narração do sonho:

"Aí, a horas certas, Ilustre Senhor Diretor, eu sonhei um movimento de gente, tanta gente! Tantanteando o seu tambor: desdigue o que tenho digue, desdigue o que tenho digue sobre fulano ou beltrano" (SALÚSTIO, 1994, p. 73).

É importante lembrar que o trabalho com literaturas africanas deve perpassar os mais variados elementos do programa de português e literatura, permitindo que se explorem a diversidade linguística e a criação de sons e imagens que caracterizem o estilo das autoras e dos 
autores estudados. Nesse sentido, a presença de neologismos como "tantanteando" e das formas verbais "desdigue" e "digue", permite o estudo dos processos de formação de palavras e como ele está diretamente relacionado ao contexto histórico cultural em que se estabelece. O mesmo trecho oferece, ainda, a possiblidade de trabalhar com as aliterações criadas pelas palavras desdigue e digue, criadoras do som de percussão que ecoa nos ouvidos dos africanos e brasileiros.

\section{"O recreio das dez e meia"}

O conto do guineense Carlos Lopes se passa no contexto colonial, quando um menino que estuda na Escola Primária Dr. Oliveira Salazar se vê em meio à dúvida do significado da palavra "mufunesa". A questão do vocabulário metaforiza as tensões enfrentadas pelas diferenças étnicas e sociais. Moema Parente Augel, em artigo a respeito da representação da nação na literatura de guerra da Guiné-Bissau (2008), afirma que, em tais obras, o conflito entre etnicidade e alteridade ganha contornos mais extremos. O conto de Lopes trabalha essa tensão pela ótica infantil do narrador que recorda sua fase escolar, em que as diferenças étnicas e linguísticas perpassam situações corriqueiras.

Este castigo foi o tema do recreio das dez e meia, sempre que eu me aproximava de um grupo diferente do meu. É que nós estávamos sempre organizados em grupos para tudo e, normalmente, separávamos o pessoal da metrópole dos da terra para não haver confusões. E para que os de lá não percebêssemos o que dizíamos falávamos em "kriol" nos recreios. Era proibidíssimo falar "kriol" e isso só aumentava o interesse em fazê-lo. Quem não arrisca não petisca. E daí que o "kriol" passasse a ser linha de demarcação (LOPES, 2002, p. 119).

O castigo de que trata o narrador se deu pelo fato do "S" da fivela de seu cinto estar um pouco torto e, por isso, ele ter sido mandado para o fim da fila pela aparência desmazelada. Os amigos chamaram tal situação, provocada por esse "S" torto, uma "mufunesa", termo, para ele, desconhecido, cuja dúvida não poderia transmitir à professora, pois era proibido falar kriol na escola. Nesse conto a função ideológica da língua se mistura com a questão da alteridade apontada por Moema Parente Augel. O cenário escolar do conto contribui ainda mais para o debate sobre o papel ideológico da língua. No contexto em que esse conto foi trabalhado, uma turma de nono ano do ensino fundamental, surgiram questionamentos tais como: que palavras podemos usar na escola? Quais devemos evitar? Como as diferentes variantes do português são vistas no contexto escolar? Por que o kriol, ou crioulo, era proibido? Por esse caminho podemos chegar, por exemplo, às línguas faladas no Brasil colonial e seus resíduos, como o nheengatu, a língua geral brasileira, baseada no tupi, proibida no século XVIII, e ao vocabulário bantu e nagô, aprofundando a pesquisa para além da lista de palavras indígenas e africanas que compõem nosso vocabulário, levando em consideração as implicações culturais e políticas dessas matrizes linguísticas até os dias de hoje. 
Ao final do conto, o narrador já adulto, ciente do significado de mufunesa - algo azarento, triste, mesquinho etc - , reflete:

Hoje em dia agradeço ao recreio das dez e meia ter-me instruído no uso das palavras que mais se pratica no "kriol" dos nossos dias. Ajustamento estrutural, eleições, salários em atraso, falta de luz, carência de água, prostituição infantil, roubalheira, incompetência, mortes de parentes e amigos e... paredes e tectos de escola central a cair: é tudo "mufunesa"! (LOPES, 2002, p. 119)

Um texto como o de Carlos Lopes pode estar presente em aulas de Literatura, bem como em discussões sobre argumentação e poder, afinal, há sempre coisas em comum vividas entre estudantes, assim como há coisas nesse texto que em nada se parecem com as imagens da natureza exótica ou da miséria que povoa o imaginário brasileiro sobre a África. Trata-se de um país específico, Guiné-Bissau, com sua realidade própria, que, na contemporaneidade, sob a voz literária de Carlos Lopes, ganha contornos irônicos e críticos.

\section{"O Kazukuta"}

Por fim, trazemos o exemplo do trabalho, no sexto ano do ensino fundamental, com o conto "O Kazukuta", do angolano Ondjaki. Assim como os demais, tal conto não traz uma atmosfera que remeta às noções estereotipadas da África. O conto, integrante do livro $O s d a$ minha rua, narra poeticamente a brincadeira das crianças, enquanto o tio Joaquim dá banho no velho cachorro Kazukuta. A descrição do cão, a atmosfera infantil e melancólica preparam o leitor para a notícia da morte da tia também narrada no conto. Assim, este se inicia: "Nós estávamos sempre atentos à queda das nêsperas, das pitangas e das goiabas, e era mesmo por gritarmos ou por corrermos que o Kazukuta acordava assim no modo lento de vir nos espreitar, saía da casota dele a ver se alguma fruta ia sobrar para a fome dele" (ONDJAKI, 2007, p. 27).

Temos a impressão, logo de início, que o narrador é uma criança, o que se confirma no decorrer da leitura. Essa relação entre memória, realidade e ficção é muito importante para jovens leitores e produtores de texto, pois muito do que estudantes do sexto ano escreverão em suas produções textuais parte da memória vivida e das histórias ouvidas e lidas ao longo da infância.

Há uma percepção muito nítida, nas produções desses estudantes, da influência das narrativas ocidentais, em especial estadunidenses, que trazem cenários frios e parques cobertos de folhas no outono. O "Kazukuta" traz em seu título o nome inusitado do cachorro, além da presença das frutas, da sintaxe e do vocabulário que, apesar de facilmente compreendidos por estarem em português, deslocam o centro da história para um lugar novo. Izabel Cristina da Rosa Gomes dos Santos explica, em seu artigo "Infância e memória em Ondjaki: voando pelo tempo", que:

As palavras, portanto, movem um pensar em busca de compreender o que, de 
fato, a infância (nos) ensina. Seguindo, nesse lugar de encontro entre infância e literatura, vale anunciar a ancoragem nos estudos da infância que propõem construir um educar potencializado para pensar o mundo, permitindo ver a novidade que as crianças trazem consigo, aceitando o risco do desconhecido e do inusitado, e, assim, redimensionar as práticas cotidianas nos contextos educacionais (2014, p. 82).

Ou seja, criança ensina criança. Sair do lugar comum da literatura canônica e eurocentrada é oferecer ao estudante a oportunidade de ter curiosidade sobre outros lugares e outras formas de pensar. Questionar por que razão ele diz "Kazukuta saía de sua casota" e não de sua casinha. Por que o narrador diz "a ver" e não "vendo"? Quais das frutas citadas no conto também são apreciadas por nós? Entre outras percepções e sensibilidades, quais rompem com uma ideia de brutalidade e sofrimento ligada às crianças africanas?

\section{Considerações finais}

As contribuições apresentadas neste texto são limitadas a sugestões de aplicação da lei 10.639/03 que já foram realizadas em salas de aula das redes estadual e federal do Rio de Janeiro. Além dos contos aqui citados, muitos outros textos, de diferentes gêneros, foram usados para elaboração de planos de aula para diversas séries. Não apenas textos africanos, como também textos brasileiros de autoria negra com temática relacionada às africanidades ou não. Entendemos que não só os conteúdos dos textos, como também a valorização da autoria estão dentro do universo de possibilidades aberto pela lei 10.639/03, uma vez que um dos objetivos desta $e ́$ valorizar as literaturas e as culturas africanas e afro-brasileira, bem como o conhecimento produzido pelos africanos do continente e da diáspora.

Acreditamos que a literatura é fundamental para promover as aproximações entre o Brasil e a África, não só em relação ao nosso passado comum de culturas e tradições, mas ao nosso presente que ainda recorre a estereótipos desumanizadores para fazer referência aos africanos e os negros brasileiros. A literatura aponta a lança para as histórias de luta e resistência, para a poesia do desejo de ser e acerta no nosso devir de povo que não aceita a continuidade da colonização mental dentro do espaço escolar.

\section{REFERÊNCIAS}

AUGEL, Moema Parente. Os segredos da "Barraca". A representação da nação na literatura de guerra da Guiné-Bissau. Revista Crioula, 2008. Disponível em: https://www.revistas.usp.br/ crioula/article/view/54039 Acesso em 13 de outubro de 2018.

BRASIL. Lei 10.639/2003, de 9 de janeiro de 2003. Altera a Lei n ${ }^{\circ}$ 9. 394, de 20 de dezembro 
de 1996. Diário Oficial da União, Poder Executivo, Brasília. Disponível em: http://www.planalto.gov.br/ccivil_03/LEIS/2003/L10.639.htm Acesso em 14 de outubro de 2018.

Diretrizes Curriculares Nacionais para a Educação das Relações Étnico -raciais e para o Ensino de História e Cultura Afro-brasileira e Africana. Brasília: Ministério da Educação, 2004.

Disponível: http://www.acaoeducativa.org.br/fdh/wpcontent/uploads/2012/10/DCN-s-Educacao-das-Relacoes-Etnico-Raciais.pdf Acesso em 14 de outubro de 2018.

DALCASTAGNE, Regina. Por que precisamos de escritoras e escritores negros? In: SILVA, Cidinha da (ORG). Africanidades e relações raciais: insumos para políticas públicas na área do livro, leitura, literatura e bibliotecas no Brasil. Brasília: Fundação Cultural Palmares, 2014.

LOPES, Carlos. "O recreio das dez e meia”. In: SECCO, Carmem Lúcia Tindó Ribeiro. Apostila de prosa das cinco literaturas de língua portuguesa. Rio de Janeiro: UFRJ, 2002.

MIRANDA, Maria Geralda de; SANTOS, Rosenilda Roberto dos. "Linguagens em diálogo no ensino da cultura e da história africanas". In. Cadernos do CNLF, Vol. XVII, No 04. Rio de Janeiro: CiFEFiL, 2013, p. 129-137.

MUNANGA, Kabengele. As origens africanas do Brasil contemporâneo: histórias, línguas, culturas e civilizações. São Paulo: Global, 2009.

SALÚSTIO, Dina. "A indústria de tambores". In: SECCO, Carmem Lúcia Tindó Ribeiro. Apostila de prosa das cinco literaturas de língua portuguesa. Rio de Janeiro: UFRJ, 2002.

SANTOS, Izabel Cristina da Rosa Gomes dos. Infância e memória em Ondjaki: voando pelo tempo. Abril - Revista do Núcleo de Estudos de Literatura Portuguesa e Africana da UFF, Vol. $6, \mathrm{n}^{\circ} 13,2^{\circ}$ sem., nov. 2014, p. 81-94.

ONDJAKI. Os da minha rua. Rio de Janeiro: Língua Geral, 2007. 